\title{
Fatores influenciadores na Cultura e no Clima Organizacional que refletem na Motivação, Liderança e Comunicação de uma Empresa de juazeiro do Norte - CE
}

\author{
Cícera Fernandes Siqueira e José Leandro de Almeida Neto
}

\begin{abstract}
Resumo: Este trabalho tem o objetivo de apresentar um estudo sobre fatores que influenciam na cultura e no clima organizacional, promovendo reflexos na motivação, liderança e comunicação de uma empresa de Juazeiro do Norte-CE. A organização pesquisada é da área hospitalar e a pesquisa caracteriza-se como quantitativa, onde os dados foram obtidos através de um questionário com perguntas fechadas, contendo respostas com cinco pontuações. Os questionários foram aplicados a trinta dos sessenta colaboradores ativos. Em fim, os resultados obtidos apresentam informações importantes que servirão para auxiliar os gestores na tomada de decisão relativa ao processo de melhoria da empresa, que poderão suprir as necessidades dos colaboradores e elevar o nível de satisfação dos mesmos.
\end{abstract}

Palavras-Chave: Cultura organizacional, Clima organizacional, Variáveis, Colaboradores.

\section{Factors That Influence Culture and Organizational Climate and Reflect on Motivation, Leadership and Communication of a Company in Juazeiro do Norte - CE}

\begin{abstract}
This work aims to present a study on factors influencing organizational culture and climate, promoting reflections on motivation, leadership and communication of a company Juazeiro-EC. The company studied is the hospital area and research is characterized as quantitative, where the data were obtained through a questionnaire with closed questions, with answers containing five scores. Questionnaires were administered to thirty of the sixty active contributors. In the end, the results have important information that will serve to assist managers in making decisions concerning the improvement of the business process, which could meet the needs of employees and raise the level of satisfaction.
\end{abstract}

Keywords: organizational culture, organizational climate, Variables, Employees.

Introdução

A cultura organizacional vem sendo hoje um objeto de estudo de grande importância para as organizações no mundo todo. Ela apresenta um forte e crescente impacto no desempenho das empresas, sendo o clima um reflexo da cultura. Destaca-se que independente do tamanho, toda empresa tem sua cultura, ou seja, sua identidade, onde essa é passada para os colaboradores.

\footnotetext{
${ }^{1}$ Graduada em Gestão de Recursos Humanos pela Faculdade de Ciências Aplicadas Dr. Leão Sampaio. Aluna Concludente do curso de PósGraduação em Gestão Estratégica do Capital Humano.E-mail:cicerafhf@gmail.com.

${ }^{2}$ Professor Especialista da Faculdade de Ciências Aplicadas Dr. Leão Sampaio. Mestrando em Ciências da Educação pela Universidade Lusófona - Lisboa-Pt . E-mail: jla.neto@hotmail.com.
} 
Para Chiavenato (2010) "O clima organizacional é favorável quando proporciona satisfação das necessidades pessoais dos participantes, produzindo elevação da moral interna. É desfavorável quando proporciona frustração daquelas necessidades".

Neste sentido entende-se que as organizações precisam observar e acompanhar de perto seu ambiente, no entanto são as pessoas que o compõem, visto que é essencial para o desenvolvimento da empresa o capital humano, pois não adiantam investimentos em tecnologias e equipamentos se não houver pessoas com habilidades para lidar com esses fatores.

Assim, antes de medir os fatores que influenciam no Clima e na Cultura de uma empresa, é melhor entender os valores, os costumes e as crenças principais do grupo, considerando gestores e demais funcionários. Para tanto, considera-se que quando não há verdadeira qualidade de vida no trabalho, a cultura e o clima apresentam-se como desfavoráveis dentro da empresa, pois os resultados proporcionados são: desmotivação, baixa produtividade, clientes insatisfeitos etc.

Segue definição da cultura:

\begin{abstract}
A cultura é um sistema de crenças (como as coisas funcionam) e valores (o que é importante) compartilhados (vivenciado por todos) e que interagem com (penetração nos sistemas e subsistemas) as pessoas, as estruturas e mecanismo de controle para produzir (efeitos as normas de comportamento características daquela organização (como fazemos das coisas por aqui). (MOURA,2010 apud LUZ,2010, p. 15)
\end{abstract}

Sendo assim, informa-se que o presente estudo foi realizado em uma empresa de prestação de serviços relativos à saúde, de médio porte, dividida em dez setores, localizada em cidade de Juazeiro do Norte - CE.

Este trabalho tem o propósito e objetivo de apresentar um estudo sobre fatores que influenciam na cultura e no clima organizacional, promovendo reflexos na motivação, liderança e comunicação de uma empresa de Juazeiro do Norte-CE.

Bispo (2006) destaca que a pesquisa de clima organizacional é uma ferramenta objetiva e segura de comprometimento com a situação atual, em busca de dados reais na gestão de recursos humanos.

Através do resultado obtido, é possível melhorar o ambiente de trabalho e identificar quais variáveis precisam de atenção especial. O diagnostico da pesquisa pode auxiliar aos gestores da empresa na tomada de decisões e na implantação de programas que promovam as melhorias necessárias para a satisfação dos colaboradores. 


\section{Cultura Organizacional}

Entende-se que a Cultura está presente em toda e qualquer organização, independente do tamanho da empresa. Quando um colaborador entra na organização, é importante que ele conheça a cultura da empresa como também faça parte dessa cultura. Segundo Robbins (2002) são várias as maneiras que se pode transmitir uma cultura organizacional, entretanto as mais eficazes são as historias, rituais, símbolos materiais e linguagem:

a) Histórias: são comuns em grandes empresas, onde sempre se ouve falar de algum fato ocorrido em que algum gerente, ou mesmo o dono da organização, tomou alguma atitude que condizia com a cultura da organização. São essas histórias, contadas entre os colegas, que ancoram o presente no passado e fornecem justificativas e legitimidade para as práticas em curso;

b) Rituais: os rituais são sequências repetitivas de atividades que reforçam e expressam os valores que são fundamentais para uma organização, as metas e as pessoas importantes, bem como as estratégias dispensáveis.

c) Símbolos materiais: a aparência de uma organização, suas instalações, a maneira.como se vestem seus funcionários e os benefícios concedidos à diretoria, são exemplos de símbolos materiais que demonstram a cultura de uma organização;

d) Linguagem: termos exclusivos utilizados em determinadas empresas para descrever escritórios, clientes, fornecedores ou equipamentos. Funcionam como denominador comum que une os membros de uma cultura ou subcultura.

Quando o individuo começa a conviver em grupo, ele passa a seguir regras a fim de estabelecer uma boa convivência com o grupo. Não há cultura melhor ou pior, certa ou errada o que se sabe é que cada organização tem sua própria cultura.

\section{Clima Organizacional}

Clima organizacional é a maneira como os colaboradores veem seu ambiente de trabalho. Segundo Machado e Goulart (2005) o clima organizacional nasce da cultura organizacional e da necessidade de satisfação dos seus colaboradores. Já para Luz (2003) o clima organizacional é uma ferramenta que permite medir, no ambiente de trabalho, o grau de satisfação dos colaboradores. Para Chiavenato (2004) O clima organizacional é favorável quando proporciona a satisfação das necessidades pessoais dos participantes, produzindo elevação da moral interna. É desfavorável quando proporciona frustração daquelas necessidades. 
A pesquisa de clima permiti medir o nível de satisfação dos colaboradores com a organização.

De acordo com Torres e Oliveira (2007) os estudos sobre clima organizacional são úteis por proverem um diagnóstico geral para a organização, indicando as áreas mais deficitárias. O quadro abaixo apresentado por Rizzati (2006,p.3) mostra alguns modelos de Clima.

Quadro 1- Estudo de clima Organizacional

\begin{tabular}{|c|c|}
\hline Autores & Fatores estudados \\
\hline Litwin; Stinger (1968) & $\begin{array}{l}\text { Estrutura, } \\
\text { Responsabilidade, } \\
\text { Riscos, } \\
\text { Recompensa, } \\
\text { Sentimento e apoio; } \\
\text { Conflito. } \\
\end{array}$ \\
\hline Modelo de Kolb et al. (1983) & $\begin{array}{l}\text { Conformismo; } \\
\text { Responsabilidade, } \\
\text { Padrões; } \\
\text { Recompensas; } \\
\text { Clareza organizacional; } \\
\text { Calor e apoio; } \\
\text { Liderança }\end{array}$ \\
\hline Sbragia (1983) & $\begin{array}{l}\text { Estado de tensão; } \\
\text { Conformidade exigida; } \\
\text { Consideração humana; } \\
\text { Adequação da estrutura; } \\
\text { Autonomia presente; } \\
\text { Recompensas proporcionais; } \\
\text { Prestígio obtido; } \\
\text { Cooperação existente; } \\
\text { Padrões enfatizados; } \\
\text { Atitude frente a conflitos; } \\
\text { Sentimento de identidade; } \\
\text { Tolerância existente; } \\
\text { Clareza percebida; } \\
\text { Justiça predominante; } \\
\text { Condições de progresso; } \\
\text { Apoio logístico proporcionado; } \\
\text { Reconhecimento proporcionado; } \\
\text { Forma de controle. }\end{array}$ \\
\hline Schneider (1975) & $\begin{array}{l}\text { Suporte administrativo; } \\
\text { Estrutura administrativa; } \\
\text { Preocupação com novos servidores; } \\
\text { Independência dos servidores; } \\
\text { Conflitos internos; } \\
\text { Satisfação geral } \\
\end{array}$ \\
\hline Continua... & \\
\hline
\end{tabular}




\begin{tabular}{|l|l|}
\hline Campbell et al. (1970) & Autonomia; \\
& Grau de estrutura; \\
& Orientação para recompensa; \\
& Consideração, calor humano e apoio \\
\hline La Follete; Sims (1975) & Grau efetivo em relação a outras pessoas da organização; \\
& Grau efetivo em relação à supervisão e/ou organização; Clareza \\
das políticas e promoções; Pressões no trabalho e padrões; \\
Comunicação aberta e ascendente; Risco na tomada de decisão
\end{tabular}

Fonte Rizzati (2006)

O quadro mostra os diversos tipos de modelos de clima desenvolvidos por diversos autores. A organização deve seguir aquele modelo no qual achar mais viável para alcançar os objetivos desejados.

O clima organizacional influencia o comportamento das pessoas tanto positivamente como também negativamente. Quando se tem um ambiente agradável os resultados são positivos onde todos saem ganhando, mas quando o clima não é satisfatório, todos saem perdendo. Se os pontos francos não forem logo corrigidos pode trazer sérios problemas para a organização. 


\title{
A influência da Motivação no Clima Organizacional
}

Motivação é um tema bem amplo e bastante discutido não só nas organizações, mas na sociedade como um todo. Ela é um dos fatores que influencia no clima organizacional. É necessário que as organizações estejam sempre buscando uma metodologia para elevar a motivação dos seus colaboradores. Robbins (2005) considera que indivíduos motivados se mantêm na realização de suas tarefas até que atinjam seus objetivos.

Quando a empresa motiva seus colaboradores, eles trabalham satisfeitos e acabam produzindo mais. Assim como também criam condições para que os demais colaboradores sintam-se como parte do sucesso que estão ajudando a construir "Afirma que motivação é alguma força direcionada dentro dos indivíduos, pela qual eles tentam alcançar uma meta, a fim de preencher uma necessidade ou expectativa." (SILVA, 2001, p. 221).

Gil (2010, p. 202) define assim a motivação:

\begin{abstract}
Motivação é a força que estimula as pessoas a agir. No passado, acreditava-se que essa força era determinada principalmente pela ação de outras pessoas, como pais, professores ou chefes. Hoje sabe-se que a motivação tem sempre origem numa necessidade. Assim, cada um de nós dispõe de motivações próprias geradas por necessidades distintas e não se pode, a rigor, afirmar que uma pessoa seja capaz de motivar outra.
\end{abstract}

O ser humano nunca está satisfeito com o que tem, sendo por isso que está sempre buscando mais. Quando uma necessidade é suprida, logo aparece outra no seu lugar. Maslow representa bem essas necessidades na pirâmide hierárquica.

Figura 1- Pirâmide de Maslow

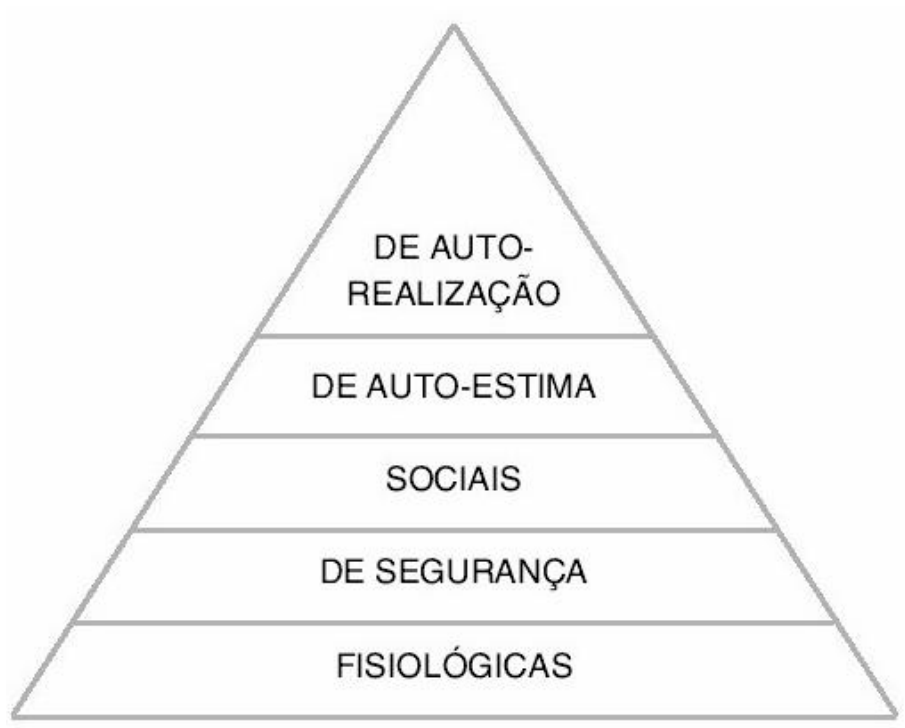

Fonte: Chiavenato, 2010a, p. 331 
$\mathrm{O}$ autor define a hierarquia das necessidades em cinco níveis, sendo o primeiro como Necessidades fisiológicas: São as necessidades que já nascem com o ser humano. É a necessidade que está como base na pirâmide. Ex: (Comida, sede, sono, respiração). Assim considerado em segundo nível as Necessidade de segurança: Estão relacionadas à segurança e proteção, onde exige um ambiente de trabalho seguro, estabelecendo limites, regras e padrões. De modo que as de terceiro nível são as Necessidades sociais: Ex (Relacionamento, família, amizades, afeição). São necessidades de Quarto nível as Necessidades de estima: relacionadas a como o indivíduo se vê e se avalia. Ex (status, confiança, conquista.). Uma vez que satisfeitas essa necessidades o autor apresenta o quinto nível como as Necessidades de auto-realização: São as necessidades mais elevadas do individuo. Encontrase no topo da pirâmide. É tornar-se o melhor que você pode ser ou é capaz de ser como (Ex: Autorealização, prestígio, excelência pessoal).

Para muitas pessoas, quando se ouve falar sobre motivação dentro da organização, logo pensam em aumento de salário, sendo que a motivação não está relacionada somente a salários e benefícios. Na maioria das vezes, pequenos gestos como reconhecimento do trabalho bem desenvolvido, um simples elogio, tanto motivam como aumenta a auto-estima dos colaboradores.

Segundo Aguiar (2005) os fatores motivadores do trabalho são aqueles que se referem à tarefa e a sua execução, mostrando uma relação direta e uma dependência entre produtividade e motivação.

\section{A influência da Comunicação e da Liderança no Clima Organizacional}

A comunicação é um ponto importante dentro da organização. Hoje existem vários meios de comunicação um dos meios mais usados nas organizações é o e-mail corporativo. Segundo Maximiano (2007) o processo de comunicação é entendido como o envio de informações e significados, dele depende a eficácia das relações interpessoais nas empresas.

Todos os processos dentro da organização dependem de uma boa comunicação. As falhas que ocorrem no processo de comunicação podem causar sérios problemas. De acordo com Lacombe (2005) a comunicação é uma via de mão dupla, onde grande parte dos problemas ocorre devido à comunicação inadequada, inoportuna ou falhas nela.

Não há uma fórmula eficiente para uma boa comunicação, a única coisa que se espera é que a comunicação seja clara, e alcance os objetivos esperados.

Considerando o que já foi registrado, informa-se que uma das principais habilidades de bons líderes é a comunicação. Pode- se dizer que o líder é o espelho da organização, pois ele tem o poder de influenciar seus liderados positivamente ou negativamente. Covey (2002), aborda a importância do 
caráter, comunicado por meio das atitudes das pessoas, das coerências entre ser e agir, para se gerar a confiança.

O líder é um dos aspectos mais importantes dentro da organização. Ele está ligado diretamente ao fracasso ou sucesso da organização. Ele tanto influencia as atitudes do grupo como motiva o grupo. De acordo com Maximiano (2007) a liderança é um papel do administrador, é ele quem influencia o comportamento de um ou mais liderados, é um processo que está intimamente ligado com a motivação.

É importante que o líder conheça e tenha um bom relacionamento com a sua equipe. Assim será fácil alcançar as metas estabelecidas e o clima será agradável. Não existe apenas um tipo de líder. Chiavenato (2004) apresenta um resumo dos três estilos de liderança:

Quadro -1 Aspectos relacionados aos estilos de liderança

\begin{tabular}{|c|c|c|c|}
\hline ASPECTOS & $\begin{array}{c}\text { LIDERANÇA } \\
\text { AUTOCRÁTICA }\end{array}$ & $\begin{array}{l}\text { LIDERANÇA } \\
\text { LIBERAL }\end{array}$ & $\begin{array}{c}\text { LIDERANÇA } \\
\text { DEMOCRÁTICA }\end{array}$ \\
\hline $\begin{array}{l}\text { Tomada de } \\
\text { decisão }\end{array}$ & $\begin{array}{c}\text { Apenas o líder decide e } \\
\text { fixa as diretrizes, sem } \\
\text { nenhuma participação } \\
\text { do grupo. }\end{array}$ & $\begin{array}{l}\text { Total liberdade ao grupo } \\
\text { para tomar decisōes, } \\
\text { com mínima intervenção } \\
\text { do líder. }\end{array}$ & $\begin{array}{c}\text { As diretrizes são } \\
\text { debatidas e decididas } \\
\text { pelo grupo, que é } \\
\text { estimulado e orientado } \\
\text { pelo líder. }\end{array}$ \\
\hline $\begin{array}{l}\text { Programação } \\
\text { dos trabalhos }\end{array}$ & $\begin{array}{c}\text { O líder dá ordens e } \\
\text { determina providências } \\
\text { para a execução de } \\
\text { tarefas, sem explicá-las } \\
\text { ao grupo. }\end{array}$ & $\begin{array}{l}\text { Participação limitada do } \\
\text { líder. Informações e } \\
\text { orientação são dadas } \\
\text { desde que solicitadas } \\
\text { pelo grupo. }\end{array}$ & $\begin{array}{c}\text { O líder aconselha e dá } \\
\text { orientação para que o } \\
\text { grupo esboce objetivos } \\
\text { e ações. As tarefas } \\
\text { ganham perspectivas } \\
\text { com os debates. }\end{array}$ \\
\hline $\begin{array}{l}\text { Divisão do } \\
\text { trabalho }\end{array}$ & $\begin{array}{c}\text { O líder determina a } \\
\text { tarefa a cada um e qual } \\
\text { o seu companheiro de } \\
\text { trabalho. }\end{array}$ & $\begin{array}{l}\text { A divisão das tarefas e } \\
\text { escolha dos colegas são } \\
\text { do grupo. Nenhuma } \\
\text { participação do líder. }\end{array}$ & $\begin{array}{l}\text { O grupo decide sobre a } \\
\text { divisāo das tarefas e } \\
\text { cada membro tem } \\
\text { liberdade para escolher } \\
\text { os colegas. }\end{array}$ \\
\hline $\begin{array}{l}\text { Comportamento } \\
\text { do líder }\end{array}$ & $\begin{array}{l}\text { O líder é dominador e } \\
\text { pessoal nos elogios e } \\
\text { nas criticas ao grupo. }\end{array}$ & $\begin{array}{l}\text { O líder assume o papel } \\
\text { de membro do grupo e } \\
\text { atua somente quando é } \\
\text { solicitado. }\end{array}$ & $\begin{array}{l}\text { O líder é objetivo e } \\
\text { limita-se aos fatos nos } \\
\text { elogios ou criticas. } \\
\text { Trabalha como } \\
\text { orientador da equipe. }\end{array}$ \\
\hline
\end{tabular}

Fonte: Chiavenato, 2004

Como se pode verificar, cada tipo de liderança tem um estilo próprio e bem definido. As organizações precisam saber escolher seus líderes, pois escolhas erradas podem levar ao fracasso. O líder tem que ser uma pessoa humana e motivada, Assim ele influenciará sua equipe para alcançar os objetivos desejados pela organização. 


\section{Condições de Trabalho}

Condições de trabalho são todos os meios que a empresa oferece para o desenvolvimento das atividades. Pontos como segurança, iluminação, ventilação são elementos que devem ser considerados um fator influenciador do clima organizacional.

Segundo Carol Dweck,

"O esforço é uma das coisas que dão sentido a vida. Significa que nos importamos, que algo é importante para nós e que estamos dispostos a trabalhar por isso. Nossa existência seria pobre se não dispusemos a valorizar as coisas e não nos comprometêssemos com trabalho em sua direção" (CAROL DWECK, 2010, p.111).

Zeithaml e Bitner (2003) lembram que além destas condições físicas do ambiente de trabalho, outras condições ambientais, como iluminação, musica, aroma e cores podem afetar a maneira como as pessoas sentem, pensam e respondem para a realização dos serviços.

As condições de trabalho interferem não só na satisfação e no clima, mas como também na qualidade de vida dos colaboradores. Quanto mais favoráveis forem as condições do ambiente, maior será o nível de rendimento dos colaboradores e segundo Hunter (2004), criar um ambiente saudável é imprescindível para promover o crescimento da organização.

\section{Método}

O presente estudo foi classificado quanto à finalidade com exploratório e descritivo. Exploratório, pois busca fazer um levantamento bibliográfico sobre o tema. Descritivo, pois procura identificar os fatores que influenciam na cultura e no clima da organização através de questionários aplicados. De acordo com Gil (2007), A pesquisa exploratória tem como objetivo proporcionar maior familiaridade com o problema, ou seja tornar-los mais claro e compreensivo, bem mais abrangente as ideias e as construções de hipóteses. Quanto aos meios, é classificada como de campo e bibliográfica. Enquadra-se como pesquisa de campo, pois foram aplicados questionários diretamente aos colaboradores da organização, onde foi feito análise quantitativa dos dados coletados. A pesquisa é bibliográfica, pois teve como base livros, artigos, redes eletrônicas, para um aprofundamento do assunto abordado.

A pesquisa em questão tem como universo(sessenta) colaboradores devidamente ativos. A aplicação dos questionários foi realizada em junho de 2014, sendo que a amostragem é não probabilística por acessibilidade ou conveniência. Os questionários foram aplicados a 30 (trinta) dos 60 colaboradores, sendo que os demais se encontravam de férias e/ou não quiseram responder. 


\section{Caracterização da Empresa}

Fundada em 1973, pelo Dr. Alberto Leite Teixeira, a empresa foi adquirida por quatro médicos em 1984 com muito esforço e sucessivas ampliações. Com 30 (trinta) anos no mercado, a organização em estudo tornou-se que hoje se vê como uma das mais bem sucedidas no seu seguimento, considerando a Região do Cariri.

A Missão da organização é promover a saúde, através da excelência no atendimento, prestando serviço hospitalar de alta qualidade a todos os nossos clientes. Já sua visão é ser hospital de grande referencia na região, em atendimento e serviço de alta qualidade nas especialidades oferecidas, valorizando o corpo clínico com produtos competitivos e inovadores, no modelo de gestão autosustentável. Os valores da empresa são: acolhimento e respeito, comprometimento e efetividade, valorização e desenvolvimento, calor humano, ética, compromisso Institucional.

\section{Apresentação e Analise dos Resultados}

Será apresentada a análise dos dados coletados através da pesquisa. As questões sócio demográficas dos colaboradores serão apresentadas em forma de tabela e a parte das perguntas específicas será em forma de gráfico para uma melhor compreensão.

Tabela 2 - Características sócio demográficas e ocupacionais dos colaboradores.

\begin{tabular}{l|l|l}
\hline Características & $\mathbf{N}^{\mathbf{0}}$ & $\%$ \\
\hline Faixa etária & & \\
$18-20$ & 5 & 17 \\
$21-25$ & 4 & 13 \\
$26-30$ & 3 & 10 \\
$31-35$ & 5 & 17 \\
$36-40$ & 3 & 10 \\
$41-45$ & 4 & 13 \\
$46-50$ & 2 & \\
$51-55$ & 3 & 7 \\
$56-60$ & 1 & 3 \\
$>61$ & 0 & 0 \\
\hline Sexo & & \\
Masculino & 10 & 33 \\
Feminino & 20 & 67 \\
\hline Renda(\$) & 9 & 30 \\
$<724,00$ & 11 & 37 \\
$724,00-1.356,00$ & & \\
\hline
\end{tabular}




\begin{tabular}{|c|c|c|}
\hline $\begin{array}{l}1.357,00-2.034,00 \\
2.035,00-2.712,00 \\
2.713,00-3.390,00 \\
3.390,00-4.746,00 \\
4.747,00-6.78000 \\
>6.781,00\end{array}$ & $\begin{array}{l}7 \\
0 \\
1 \\
1 \\
1 \\
0\end{array}$ & $\begin{array}{l}23 \\
0 \\
3 \\
3 \\
3 \\
0\end{array}$ \\
\hline $\begin{array}{l}\text { Escolaridade (ensino) } \\
\text { Fundamental Incompleto } \\
\text { Fundamental Completo } \\
\text { Médio Incompleto } \\
\text { Médio completo } \\
\text { Superior Incompleto } \\
\text { Superior Completo } \\
\text { Pós graduado } \\
\text { Outros }\end{array}$ & $\begin{array}{l}2 \\
4 \\
1 \\
14 \\
3 \\
3 \\
2 \\
1\end{array}$ & $\begin{array}{l}7 \\
13 \\
3 \\
\\
47 \\
10 \\
10 \\
7 \\
3\end{array}$ \\
\hline \multicolumn{3}{|l|}{ Tempo de Empresa (anos) } \\
\hline $\begin{array}{l}<\text { De } 01 \\
1-2 \\
3-4 \\
5-7 \\
8-10 \\
>10\end{array}$ & $\begin{array}{l}6 \\
8 \\
2 \\
3 \\
0 \\
11\end{array}$ & $\begin{array}{l}20 \\
27 \\
6 \\
10 \\
0 \\
37\end{array}$ \\
\hline
\end{tabular}

Fonte: Dados da pesquisa (2014)

Dos 30 colaboradores, a grande maioria é do sexo feminino com $67 \%$, sendo que $33 \%$ é do sexo masculino. Pode-se identificar um perfil bem equilibrado, onde se observa um empate entre algumas das idades. Apresentando-se de $17 \%$ entre 18 a 20 anos e 31 a 35 anos. Mostra-se que 13\% entre 21 a 25 anos e 41 a 45 anos. Outro empate de $10 \%$ entre 26 a 30 anos, 36 a 40 anos. Verifica-se também que há uma porcentagem bem considerada nas idades de 41 a 60 anos que chega a soma 33\% dos colaboradores questionados.

Foi perguntado sobre a renda individual, sendo que após a análise detectou-se que a maioria, representada por $37 \%$, recebe o salário entre $\mathrm{R} \$ 724,00$ à $\mathrm{R} \$ 1.356 .00$, seguido com $30 \%$ ficaram os 
que ganham o valor menor que $\mathrm{R} \$ 724,00$ e $23 \%$ os que recebem o salário entre $\mathrm{R} \$ 1.357 .00$ à $\mathrm{R} \$$ $2.034,00$.

Referente à escolaridade, a grande maioria, $47 \%$ possui o ensino médio completo, onde $3 \%$ representam os colaboradores com ensino médio incompleto, sendo que $10 \%$ de nível superior incompleto, $10 \%$ com superior completo, o ensino fundamental completo representa $13 \%$ e do fundamental incompleto7\%, pós graduado $7 \%$ dos colaboradores e outros $3 \%$. Comparando a faixa etária onde $33 \%$ dos colaboradores tem até 60 anos, essa talvez seria uma causa do nível de ensino médio ser elevado.

Quanto às características ocupacionais, 37\% dos colaboradores está na empresa há mais de 10 anos. Seguido de $27 \%$ até 02 anos, $20 \%$ está na empresa há menos de um ano, sendo que $10 \%$ até 07 anos e $6 \%$ dos colaboradores até 04 anos na empresa.

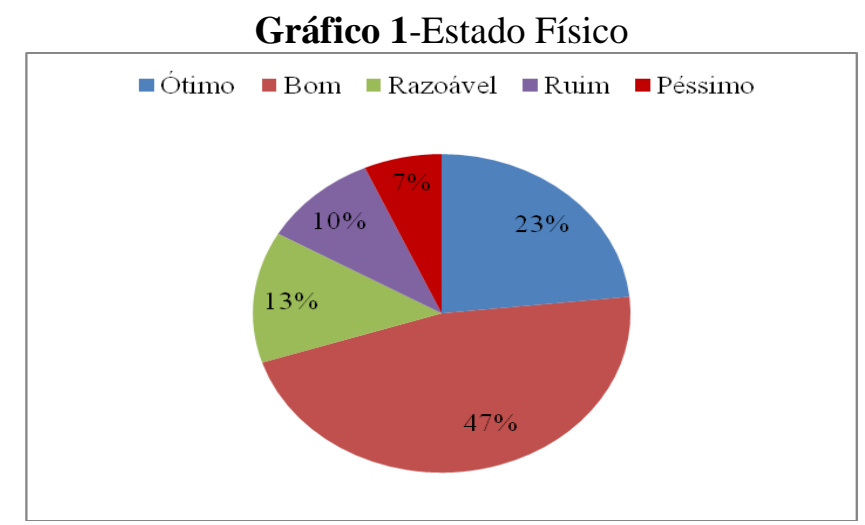

Fonte: Dados da pesquisa 2014

Entende-se que o estado físico de uma pessoa é como ela se sente em um dado momento. Onde $47 \%$ dos colaboradores consideram que estão em bom estado físico e $23 \%$ acham que estão em um ótimo estado físico.

Gráfico 2-Autonomia para desenvolver o trabalho

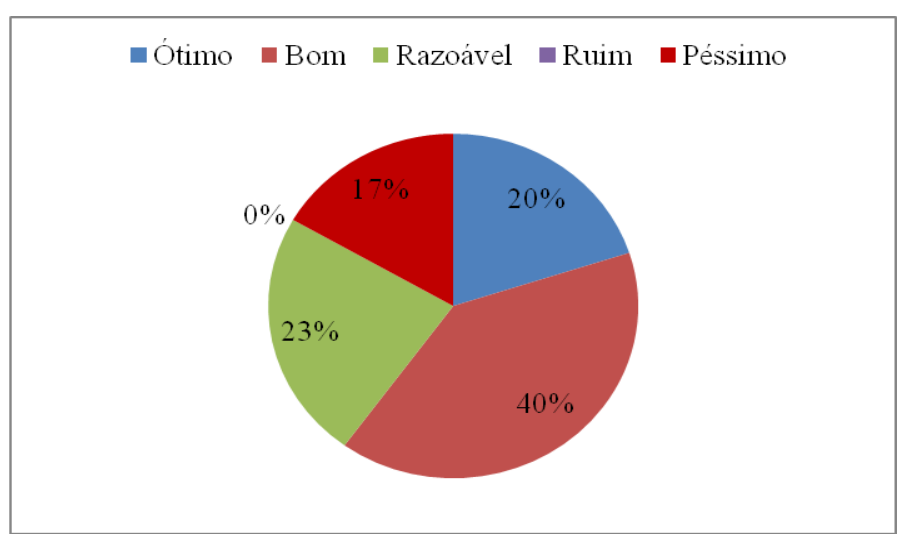

Fonte: Dados da pesquisa 2014 
Embora $40 \%$ dos resultados foram considerados bons, os colaboradores ainda não se sentem com total autonomia para desenvolver o trabalho como acham melhor. Pode se observar que $23 \%$ responderam que a autonomia é razoável e 17\% acham péssimo.

Para muitas pessoas autonomia está ligado com trabalho autônomo, ou seja, ser o seu próprio chefe. Entende-se que autonomia é ser independente ter liberdade para fazer ou decidir algo. Cabe a organização analisar a situação e ver o que pode ser mudado para melhorar esses dados. Visando até o aumento da produtividade.

Gráfico 3- Organização da rotina de trabalho para melhor aproveitamento.

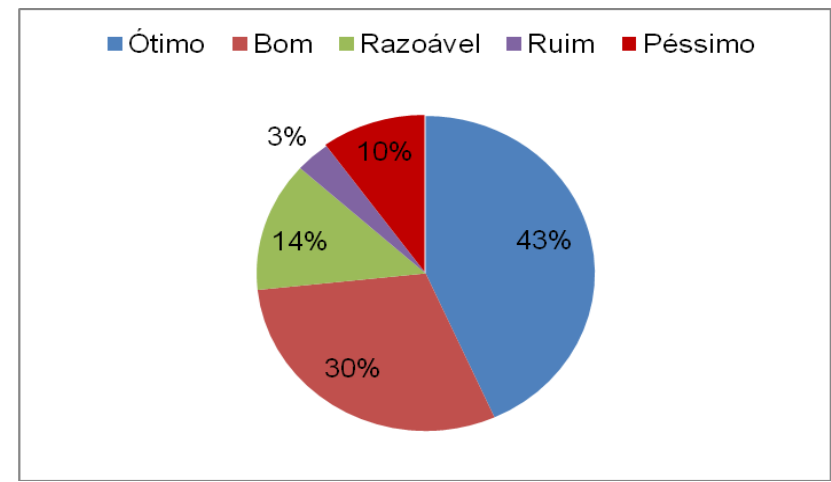

Fonte: Dados da pesquisa 2014

Nada melhor do que o próprio colaborador para organizar sua rotina de trabalho com expectativas de ver e sentir o trabalho realizado com sucesso. Nota-se que $43 \%$ dos colaboradores preferem e acham ótimo organizarem suas tarefas no ambiente de trabalho, onde $30 \%$ dos questionados acham bom organizarem suas. Assim adéquam suas rotinas diárias e obtém um melhor aproveitamento na execução de suas tarefas com a organização, onde o mesmo pode até obter-se um aumento na produtividade dentro do ambiente de trabalho e até um reconhecimento por parte da organização, pois o mesmo mostrando esforço e dedicação pelo trabalho com certeza será bem visto pela organização.

Segundo Hunter (2004, p.49) "Se você não mudar a direção, terminará no mesmo lugar de onde partiu". Para ser um profissional bem reconhecido tem que fazer diferente. 
Gráfico 4 - A Comunicação entre a Diretoria e os Colaboradores

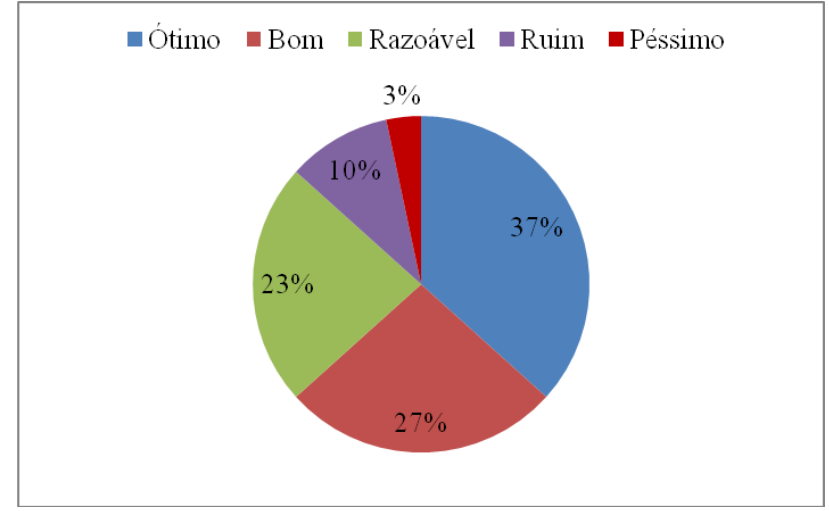

Fonte: Dados da pesquisa 2014

De acordo com Brum (2010) A comunicação é a base para qualquer relacionamento humano. Existe comunicação entre a direção e os colaboradores, prova disso é um resultado de $37 \%$ ótimo e $27 \%$ bom. Mas há também os que não estão satisfeitos com a comunicação $23 \%$ consideram a comunicação razoável. A comunicação é importante para que o colaborado se sinta totalmente envolvido com a empresa. E mantenha se sempre informado do que acontece dentro da mesma. Com esse índice de $23 \%$ a empresa deve procurar identificar onde estão as falhas no processo de comunicação para serem corrigidas.

Gráfico 5- Comunicação entre os setores

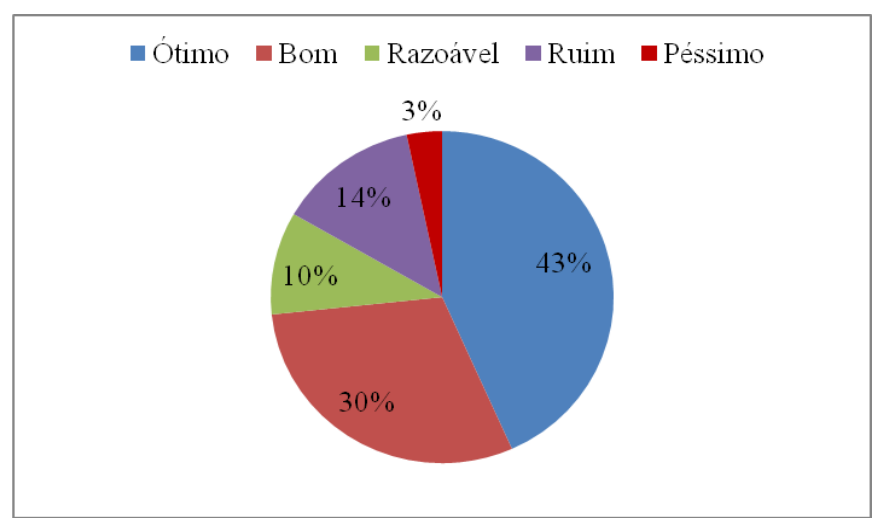

Fonte: Dados da pesquisa 2014

Existem alguns setores da empresa que são interligados e que precisam estar sempre trocando informações, ou seja, se comunicando. $43 \%$ dos colaboradores consideram uma ótima comunicação entre os setores e $30 \%$ consideram boa.. 
Pimenta (2007, p. 58) informa que "a comunicação dentro da empresa contribui para definição e concretização de metas e objetivos, além de possibilitar a integração e equilíbrio entre seus componentes (departamentos, áreas, etc.)"

Gráfico 6 - Comunicação entre lideres e liderados.

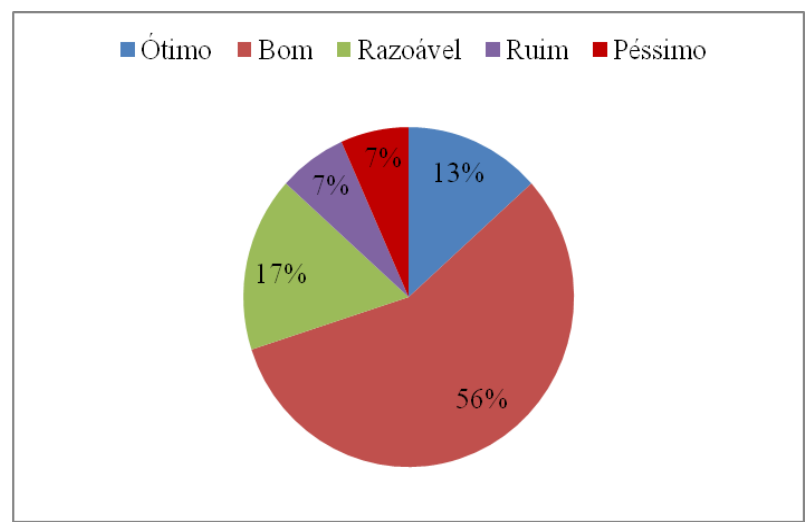

Fonte: Dados da pesquisa 2014

Para Ribeiro (2008) um líder precisa entender que tudo é comunicação, o que você faz e não somente o que você fala. A comunicação entre lideres e liderado é importante para um bom relacionamento entre os mesmo. Verificou-se que na pesquisa voltada a comunicação $56 \%$ dos colaboradores tem uma boa comunicação com seus líderes, ao passo que $17 \%$ dos colaboradores não tem uma boa comunicação com seus líderes pois acham que a comunicação é razoável.

Gráfico 7- Considerações sobre o profissionalismo dos Gestores.

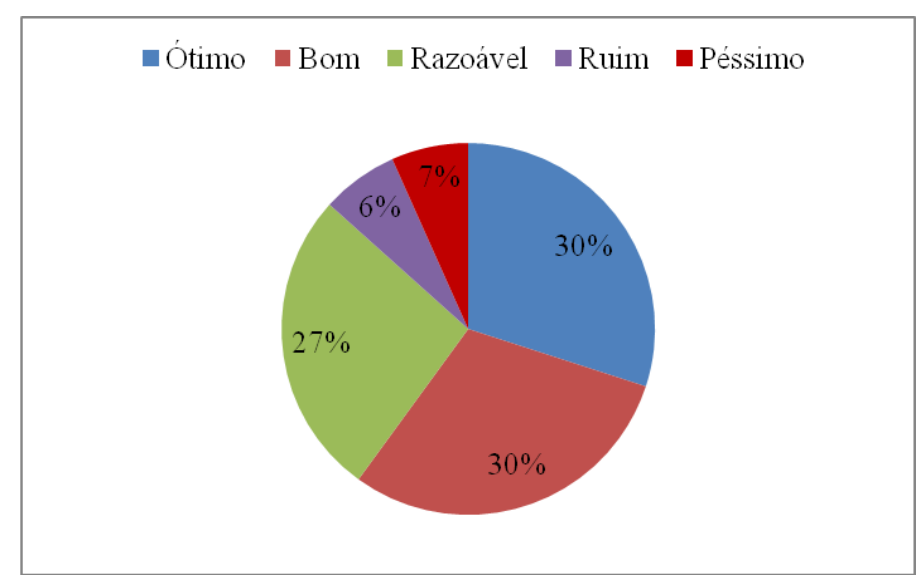

Fonte: Dados da pesquisa 2014 
É importante para a organização ter os melhores profissionais no seu quadro de colaboradores $30 \%$ acham que os gestores são ótimos profissionais e 30\% acham bom. A organização deve procurar mudar essa opinião que os colaboradores têm dos seus gestores.

Farber (2006, P. 150, "Sempre que for possível, assegure-se de que ações e condutas estejam à altura das palavras, das ideias, das promessas e dos compromissos que você verbaliza e sejam o verdadeiro reflexo deles.

Gráfico 8 - Acessibilidade do líder.

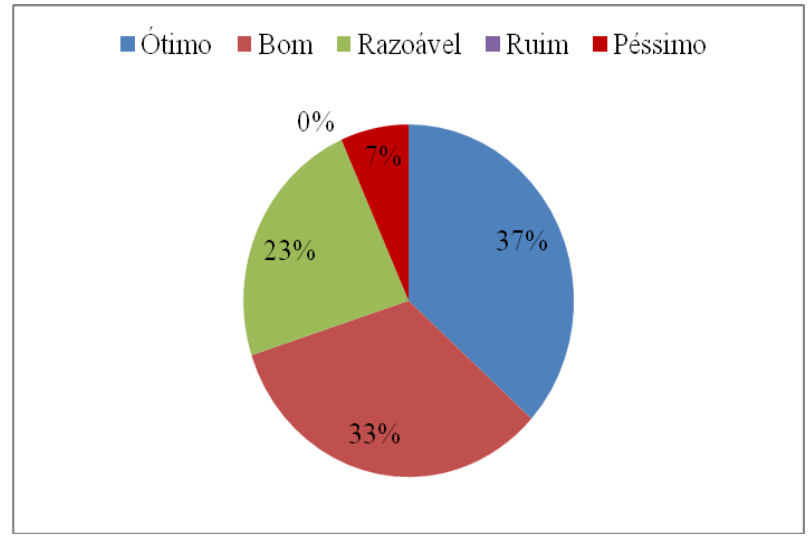

Fonte: Dados da pesquisa 2014

O líder é o espelho da sua equipe, para que esse espelho transmitam reflexos sempre positivos é necessário manter um bom relacionamento entre ambos. O líder precisa saber ouvir e saber o que se passa entre os seus liderados. $37 \%$ dos seus colaboradores responderam que a acessibilidade do seu líder é ótima e $33 \%$ acham quem é bom.

Conforme diz Jordão (2010, p. 03): "Liderar é a arte de conduzir as pessoas para que façam o que é necessário por livre e espontânea vontade. É conseguir que seus liderados queiram fazer o que precisa ser feito".

Gráfico 9-Satisfação com o salário atual

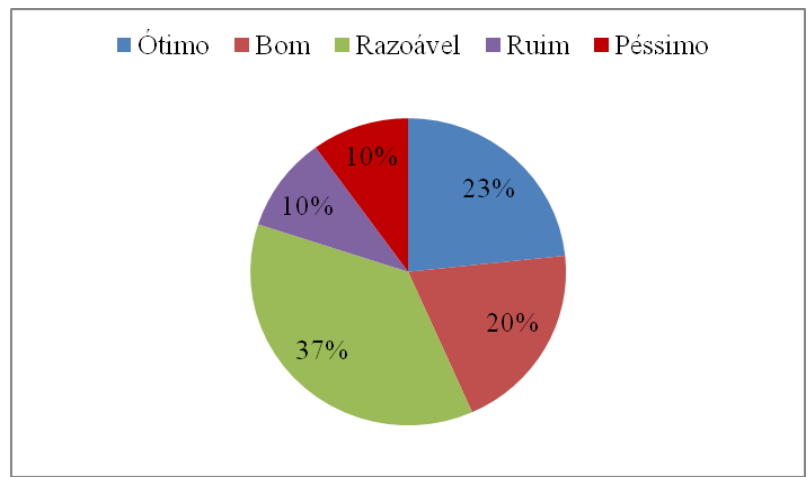

Fonte: Dados da pesquisa 2014 
Para Milkovich Boudreau (2000) A remuneração é o ato de recompensar em pagamento o serviço prestado por alguém; assim a questão central é transformar a visão atual da remuneração, ou seja, o salário em troca de trabalho realizado, caracterizando um fator de custo para uma visão da remuneração como fator de aumento da competitividade. A maioria dos colaboradores não está satisfeito com o salário que estão recebendo. Pode-se observar que 37\% dos colaboradores acha razoável o salário que recebem, em contra partida dos colaboradores $23 \%$ encontra-se satisfeitos com o salário recebido pela empresa e acham ótima.

Gráfico 10 -Remuneração oferecida pela empresa

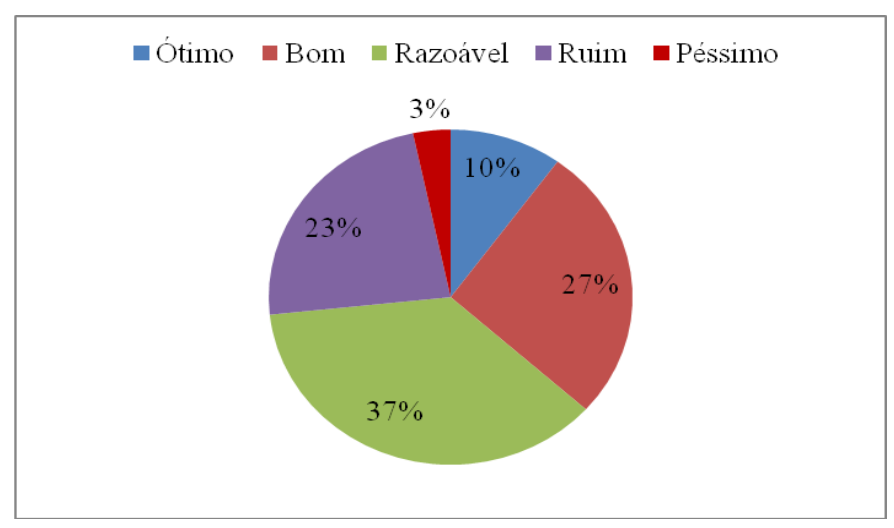

Fonte: Dados da pesquisa 2014

De acordo com Cassar (2008) Remuneração é a soma do pagamento direto com o pagamento indireto, este último entendido como toda contraprestação paga por terceiros ao trabalhador, em virtude um contrato de trabalho que este mantém com o empregador. A maioria dos colaboradores com $37 \%$ acham que a remuneração que recebem é razoavelmente adequada, Já $27 \%$ acham que é boa e $23 \%$ responderam que é ruim.

Gráfico 11 -Aptidão para assumir maiores ou mais responsabilidades

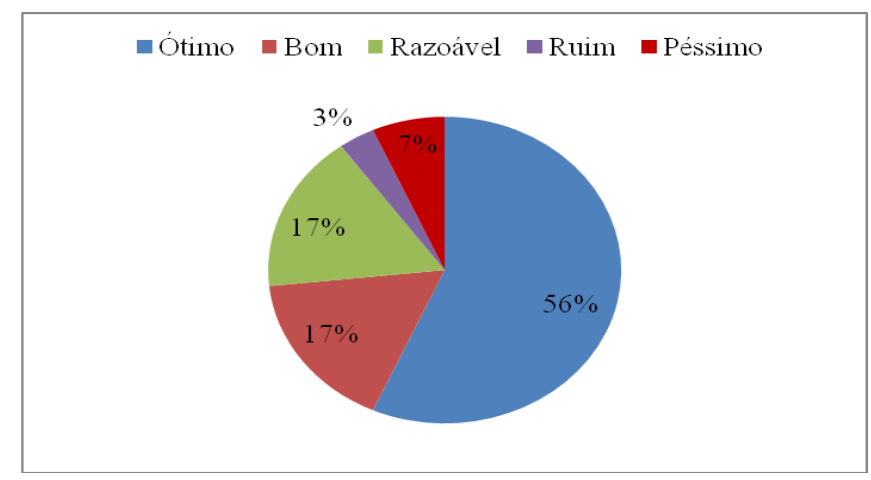

Fonte: Dados da pesquisa 2014 
Ser responsável é a capacidade de cumprir com todas as obrigações que lhe são delegadas. $56 \%$ dos colaboradores se sentem aptos para assumirem as responsabilidades que lhes são confiadas. Já para os demais colaboradores houve um empate de $17 \%$ entre bom e razoável. Embora mais da metade dos colaboradores se sintam preparados para assumirem novas responsabilidades os demais ainda não se sentem preparados para assumirem.

Gráfico 12 - Oferecimento de oportunidades para desenvolvimento e crescimento profissional

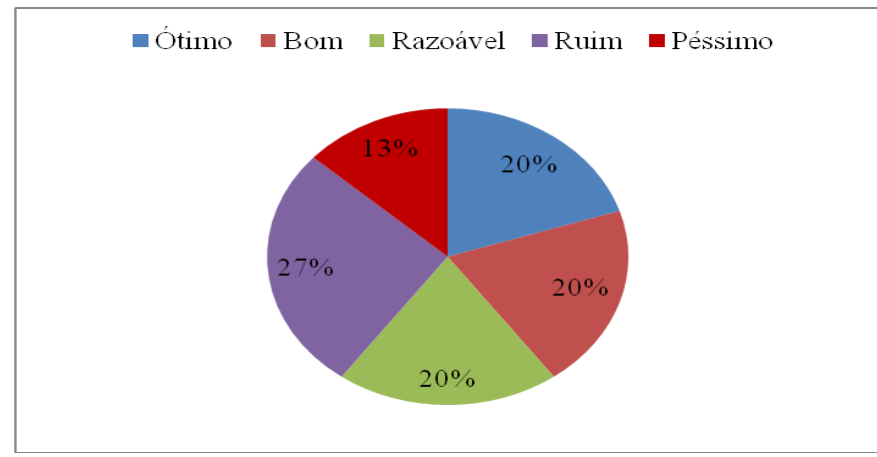

Fonte: Dados da pesquisa 2014

Existem varia maneiras de oferecer oportunidades para os colaboradores crescerem e se desenvolverem profissionalmente. Uma delas é através de cursos de aperfeiçoamentos específicos, tais cursos proporcional melhoria nas habilidades do indivíduo. Quando perguntado se a organização oferecia oportunidades de desenvolvimento e crescimento profissional os resultados não foram satisfatórios. $27 \%$ dos colaboradores responderam que é ruim, Ficando empatado com $20 \%$ ótimo, bom e razoável.

De acordo com Pequeno (2011), desenvolver pessoas não é apenas desenvolver novas habilidades e sim o desenvolvimento da capacidade e da vontade de se adaptar.

Gráfico 13 - Valorização da organização com o colaborador.

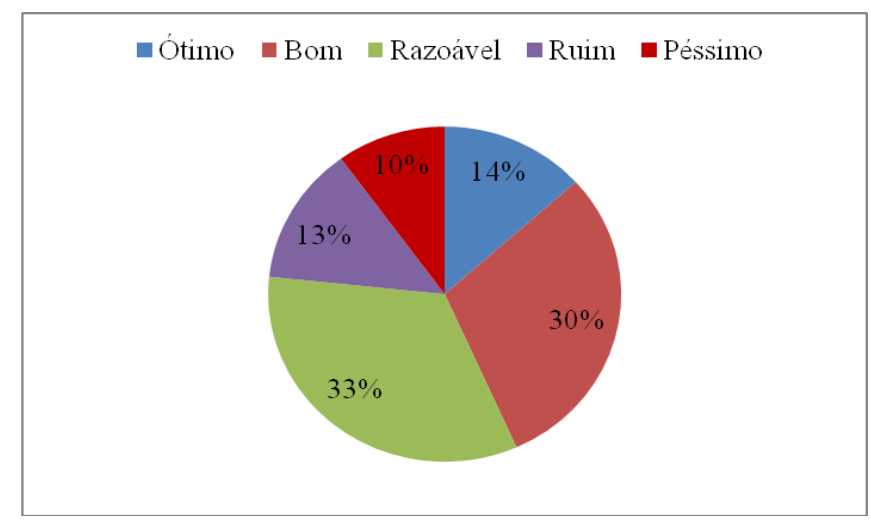

Fonte: Dados da pesquisa 2014 
Se sentir valorizado faz bem para qualquer com individuo. A maioria dos colaboradores com $33 \%$ se sentem razoavelmente valorizado pela empresa. Para outros $30 \%$ acham que a valorização é boa. É importante a empresa mudar a visão que os colaboradores têm nessa questão. Procurar valorizar os seus colaboradores.

Gráfico 14 - Higiene do ambiente

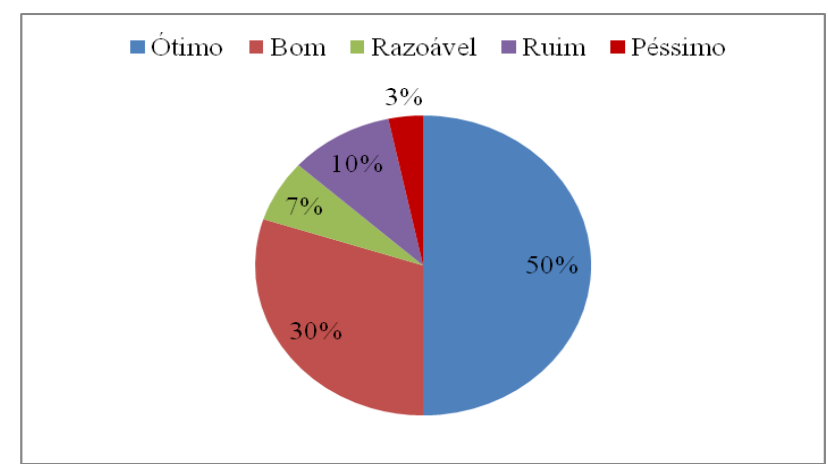

Fonte: Dados da pesquisa 2014

Higiene no ambiente de trabalho são medidas preventivas, para reduzir as doenças ocupacionais. Para Chiavenato (2004) Higiene do trabalho refere-se a um conjunto de normas e procedimentos que visa à proteção da integridade física e mental do trabalhador, preservando-o dos riscos de saúde inerentes às tarefas do cargo e ao ambiente físico onde são executadas. Relaciona-se com o diagnóstico e prevenção das doenças ocupacionais a partir do estudo e controle de duas variáveis: o homem e seu ambiente de trabalho. 50\% dos colaboradores responderam que a higiene é ótima e $30 \%$ acham a higiene boa. O que é um resultado bastante satisfatório mostra que a empresa se preocupa com as saúde dos seus colaboradores.

Gráfico 15 -Bom lugar para se trabalhar

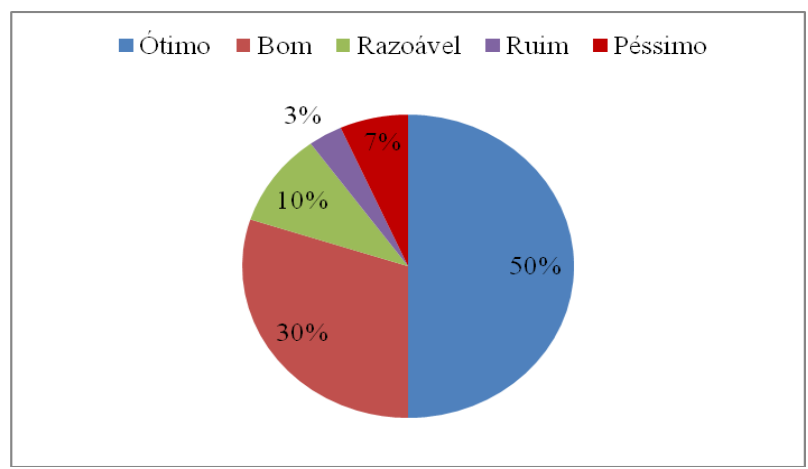

Fonte: Dados da pesquisa 2014

O ambiente de trabalho deve ser um lugar com um clima agradável, sendo assim é possível ter uma produtividade bastante positiva, acarretando valores para a empresa e colaboradores. $50 \%$ dos 
entrevistados consideram que é ótimo trabalhar na organização e 30\% dos colaboradores acham bom. Pode-se considerar um índice bastante satisfatório quando somado os dois melhores que resulta em $80 \%$ dos colaboradores se sentem muito bem no local de trabalho, É um grande prazer para qualquer empresa, saber que os seus funcionários estão trabalhando num lugar que realmente sente-se bem, Esta situação é muito agradável para uma empresa, o e o melhor de tudo é que o funcionário satisfeito produz mais.

Gráfico 16 -Ética da organização com os colaboradores, clientes e parceiros.

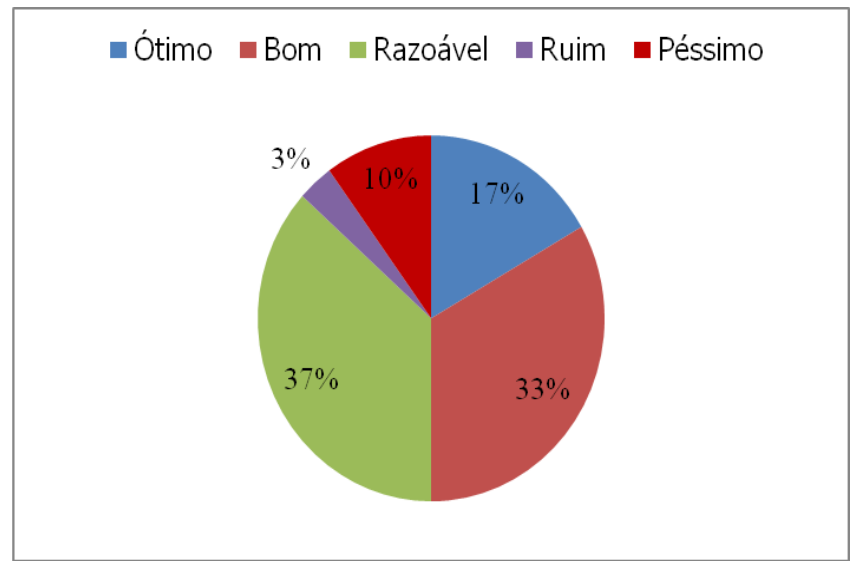

Fonte: Dados da pesquisa

Os colaboradores não acham que a ética da organização para com os colaboradores, clientes e parceiros estejam positivos. Tanto é que a maioria com 37\% acham razoável e 33\% bom acham que é bom. É importante a empresa mudar essa visão que os colaboradores têm da empresa.

Gráfico 17 - Bons exemplos dos gestores.

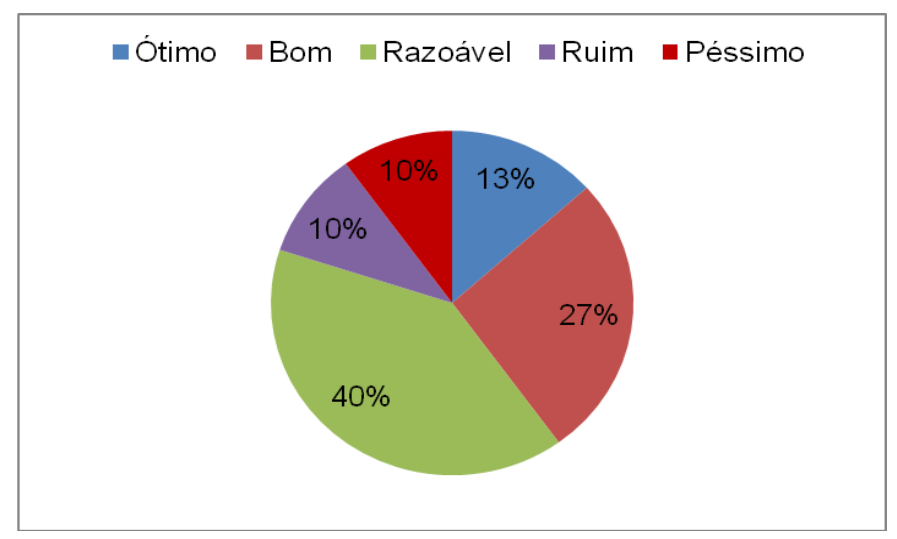

Fonte: Dados da pesquisa 
Esse é um fator bastante preocupante já que os resultados foram bastante insatisfatórios. $40 \%$ dos colaboradores acham os exemplos que os gestores dão são razoáveis. Mas para $27 \%$ dos colaboradores são bons. Cabe a empresa ver o que se pode fazer para mudar esse índice. Pois os gestores são o espelho dos seus colaboradores.

Na visão de Lacombe e Heilborn (2006), são indispensáveis para um bom administrador ter experiência, conhecimento, habilidade em lidar com as pessoas, responsabilidade e, acima de tudo, alto grau de compreensão de si próprio e da sua equipe.

\section{Considerações Finais}

A administração moderna sinaliza a importância do trabalho em equipe, sendo que as empresas estão tomando consciência do imenso valor que as pessoas; se bem lideradas, motivadas e bem satisfeitas com seu trabalho, agregam para empresa.

Assim, o trabalho apresentou os fatores como: "Ser um bom lugar para trabalhar", "Higiene no ambiente de trabalho" e "Capacidade de assumir maiores responsabilidades" com os maiores índices de satisfação dos colaboradores pesquisados, fatores estes que influenciam positivamente na cultura e no clima organizacional, causando reflexos também positivos na motivação, liderança e nas perspectivas de uma comunicação assertiva na empresa.

Observa-se ainda que a variável "autonomia para desenvolver o seu trabalho" sinalizou que $40 \%$ dos colaboradores pesquisados não avaliam este fator como adequado, onde $23 \%$ classificam como razoável e $17 \%$ péssimo. Destaca-se que a autonomia é proveniente da cultura organizacional e do estilo de liderança dos gestores, sendo que o resultado constatado sinaliza um reflexo negativo na liderança, podendo ser gerado inclusive por falhas no processo de comunicação da empresa, no que diz respeito a deixar claro para os colaboradores que eles possuem autonomia para resolver determinados problemas.

Por outro lado, os fatores "comunicação entre a Direção e Colaboradores" e "Comunicação entre os Setores" apresentaram resultados positivos, sinalizando a existência de reflexos também positivos na Liderança e na Motivação.

Vale destacar que existe uma quantidade considerável de colaboradores pesquisados que se mostram satisfeitos com a higiene do ambiente de trabalho, julgando que consideram a empresa pesquisada um bom lugar para trabalhar.

A realização desta pesquisa possibilitará aos gestores da empresa o conhecimento de informações valiosas para gerenciar a cultura e o clima da empresa, despertando inclusive interesse na realização de outras pesquisas que poderão auxiliar na melhoria contínua do empreendimento. 


\section{Referências}

AGUIAR, Maria Aparecida Ferreira de. Psicologia aplicada à administração: uma abordagem interdisciplinar. São Paulo: Saraiva, 2005.

BISPO, Carlos Alberto Ferreira. Um novo modelo de pesquisa de clima organizacional. Produção, SãoPaulo, Ago. $2006 . \quad$ Disponível em: http://www.scielo.br/scielo.php?script=sci_arttext\&pid=S010365132006000200007\&lng=pt\&nrm=iso , acessado em 11/08/2014

BRUM, Analisa de Medeiros. Endomarketing de A a Z: como alinhar o pensamento das pessoas á Estrategia de Empresa.1 ed. Rio de Janeiro: Integrar e Editora,2010.

CASSAR, Volia Bonfim, Direito do Trabalho.2ª ed. Impetus, Niterói 2008.

CAVALCANTY, Vera Lucia, Marcelo Carpilovsky, Myrian Lund< Regina Arezynska Lago. Liderança e Motivação- $3^{a}$ reimpressão 2011- Rio de Janeiro: Editora FGV 2009.

CHIAVENATO, Idalberto. Comportamento Organizacional: a dinâmica do sucesso das organizações. $2^{\mathrm{a}}$ ed. Rio de Janeiro: Elsevier,2010a

Comportamento Organizacional: a dinâmica do sucesso das organizações. $2^{\mathrm{a}}$ ed. Rio de Janeiro: Elsevier,2010a.

Gerenciando Pessoas. $3^{\text {a }}$ ed. São Paulo: Makron Book, 2004a.

Campus, 1999.

Gestão de pessoas: o novo papel dos recursos humanos nas organizações. Rio de Janeiro:

FARBER, Steve. Liderança Radical. Rio de Janeiro: Sextante,2006.

GIL, Antônio Carlos. Como elaborar projetos de pesquisa. 4. ed. São Paulo: Atlas, 2007

, Gestão de pessoas. 1. ed. São Paulo: Atlas, 2010.

HUNTER, James C. O monge e o Executivo; tradução de Maria Conceição Fonos de Magalhães- rio de Janeiro- Sextante, 2004.

LACOMBE e HELBORN (2006), A importância do papel do administrador como gestor. Disponível em www.partes.com.br/emrhede/papeldoadministrador.asp, Acessado em 13/08/2014.

LACOMBE, Francisco José Masset. Recursos Humanos: princípios e tendências. São Paulo: Saraiva,2005.

LUZ, Ricardo. Gestão de Clima Organizacional $5^{\mathrm{a}}$ reimpressão: 2010

Gestão do clima organizacional. Rio de Janeiro: Qualitymark, 2003.

MACHADO, Alyne Maria; GOULART, Antônio Marcos A. Análise de Clima Organizacional: estudo de caso em uma agência bancária. Rio de Janeiro: VIII SEGeT(Simpósio em Excelência em Gestão e Tecnologia), 2005. 
MAXIMIANO, A. C. A. Introdução à Administração. 7. ed. São Paulo: Atlas, 2007. 404p.

MILKOVICH, George T., BOUDERAU, John W. Administração de Recursos Humanos. São Paulo: Atlas, 2000.

PIMENTA, Maria Alzira. Comunicação Empresarial. Editora Alíneia. 5a edição 2a impressão, 2007.

PINK, Daniel. Motivação 3.0: Os novos Fatores Motivacionais que buscam tanto a realização pessoal quanto profissional- Rio de Janeiro- Elsevier 2010.

RIBEIRO, João. Manual Técnico do Formando: Comportamento Organizacional. São Paulo:Editora EduWeb, 2008.

RIZZATTI, Gerson; RIZZATTI JUNIOR, Gerson; SARTOR, Vicente Volnei de Bona. Categorias de Análise de Clima Organizacional em Universidades Federais. 2006. Disponível em: http://www.anpad.org.br/admin/pdf/GPR-B2243.pdf. Acessado em 15/07/2014

ROBBINS, S. P. Administração - Mudanças e Perspectivas. São Paulo : Saraiva, 2002

Comportamento organizacional. Tradução: Reynaldo Cavalheiro Marcondes. 11. ed. São Paulo: Pearson Prentice Hall, 2005.

SILVA, Reinaldo Oliveira. Teorias da administração. São Paulo: Pioneira Thomson Learning, 2001.

TORRES, Elvia Florêncio; OLIVEIRA, José Arimatés. A influência do clima organizacional no alcance da efetividade organizacional em industrias do setor alimentícios utilizando o modelo ASH. Rio de Janeiro-RJ,2007. Disponível em: http://www.anpad.org.br. Acessado em 15/07/2014.

ZEITHAML,V. A. e BITNER, M. J. Marketing de Serviços: a empresa como foco no cliente 2. Ed. Porto Alegre: Bookman,2003.

\section{Como citar este artigo (Formato ABNT):}

SIQUEIRA, C.F. e ALMEIDA NETO, J.L.. Fatores influenciadores na Cultura e no Clima Organizacional que refletem na Motivação, Liderança e Comunicação de uma Empresa de Juazeiro do Norte - CE. Id on Line Revista de Psicologia, Fevereiro de 2015, vol.9, n.25, p. 180-202. ISSN 1981-1189. 